\title{
Corpus Alienum (Cover the perfume) in cervix Pasca masturbation (Case report)
}

\author{
Rizky Yusnida Amelia ${ }^{1 *}$, Pribakti Budinurdjaja ${ }^{2}$, Ihya Ridlo Nizomy ${ }^{3}$ \\ ${ }^{1}$ Residency Program, Department of Obstetrics and Gynecology, Faculty of Medicine of Lambung Mangkurat \\ University/Ulin Hospital, Banjarmasin, Indonesia \\ 2, 3 Division of Urogynecology and Reconstruction, Department of Obstetrics and Gynecology, Faculty of Medicine of \\ Lambung Mangkurat University/Ulin Hospital, Banjarmasin, Indonesia
}

\section{Keywords \\ Foreign body \\ Cervix \\ Masturbatio \\ Gynecological \\ Practices}

Received: 2 April 2019

Accepted: 15 July 2019

Published: 22 October 2019

\begin{abstract}
A foreign body in the vagina is a condition that does not generally occur but may be seen in obstetric and gynecological practices. Foreign bodies inserted into the vagina are often tools for masturbation and intercourse. A foreign body located in the genital tract can cause various clinical problems, including purulent vaginal discharges, scarring of the vagina, fistula formation, recurrent urinary tract infections, and infertility. To describe a case report of Vaginal Cervix Foreign Body (Perfume Bottle Cap) in a Woman after masturbation. The methode of this research was descriptive using case report. The subject was a patient who got corpus alienum in cervix pasca masturbation. The description was about clinical manifestation, support examination, and teraphy. A 20 years-old-woman came unaccompanied to the Ulin Regional Hospital Banjarmasin, presenting with a foul-smelling, yellowish-white vaginal discharge for the past 4 years. The patient confessed of she inserting a foreign body, in the form of a perfume bottle, into the genitals during masturbation. However, upon a removal attempt, the upper cap was left inside. Vaginal inspection revealed a foul-smelling, yellowish-white fluor albus. The speculum examination had shown a foreign body with the size of $+2 \mathrm{~cm}$ fixated onto the cervix. Further imaging of the pelvic, abdominal ultrasound and contrasted CT scan of the pelvic had confirmed a foreign object inserted into the cervix. The foreign body evacuation was then conducted under general anesthesia. A perfume bottle cap foreign body was found on a woman after masturbation, gave clinical manifestatons such as foul smelling and fluor albus. Support examination showed foreign body and it was evacuated under general anesthesia. Case of Gynecology Obstetrics field in Division of Uroginecology and Reconstruction. Rare case report as source of learning in diagnosis and teraphy.
\end{abstract}

(C) 2019 The Author(s). Published by TAF Publishing

\section{INTRODUCTION}

\section{A. Background}

Corpus alienum inside the vagina is an uncommon case, but can occur in daily practice. The corpus alienum found in the vagina is often a tool used in masturbation. These objects can be inserted by the patient or sexual partners $[1,2,3]$. Following this, it was reported that a woman aged 20 years came personally complaining of smelly vaginal discharge since the last 4 years, yellowish white vaginal discharge, the patient claimed to have inserted a foreign object in the form of a perfume bottle into the genitals during martubation, but when removing the perfume bottle, the cap on the top of the perfume was left behind. inside the patient's vagina. The patient feels an object that is stuck during sexual intercourse with her husband, causing pain and injury to the patient's husband's penis. The patient admitted that there were no urination and defecation problems. The patient has not had children, with a history of having had 2 marriages. The first marriage in 2018 for 5 months later divorced because the husband complained of smells and pain during sexual intercourse. Second marriage in 2019 for 1 week. The patient has never used family planning with a blood pressure of $120 / 80 \mathrm{mmHg}$, pulse rate $88 \mathrm{x} / \mathrm{m}$, respiration $18 \mathrm{x} / \mathrm{m}$, body temperature $36.7 \mathrm{oC}$. On vaginal inspec-

\footnotetext{
* corresponding author: Rizky Yusnida Amelia

†email: drmeitria79@gmail.com
} 
tion, fluorine found yellowish-white color that smelled. In inspekulo, yellowish-white fluorine appears in the portion to the vagina, the corpus alienum is seen at the mouth of the cervix, a whitish color $+2 \mathrm{~cm}$.

On examination, it was found that the corpus alienum was attached to the cervix. The ultrasonography showed an anteflexed uterus measuring $5.5 \times 3.4 \times 4.5 \mathrm{~cm}$. The corpus alienum was seen in the fornix area anterior to the proximal vagina. On the pelvic radiograph shows a metal and plastic density corpal, transverse position in the pelvic cavity measuring $1.5 \times 3 \mathrm{~cm}$. The pelvic CT scan shows a plastic and metal density corpus alienum covered by connective tissue that attaches to the anterior fornix and anterior portion of the pars, attaches to the anterior vaginal wall (within 0.42 $\mathrm{cm}$ from the bladder based) and attaches to the posterior vaginal wall (distance $0,18 \mathrm{~cm}$ from prerectal fat), size 6.16 x $3.11 \times 3.65 \mathrm{~cm}$.

Extraction of the corpus alienum using a tenaculum failed. The patient was then treated with a diagnosis of vaginal cervical corpus alienum and planned for evacuation with narcotics. The procedure is carried out under spinal anesthesia. In the exploration of the birth canal (vaginal), a silver colored corpus alienum is obtained oblique transverse position with its apex on the upper left lateral to the base (sharp side), right lower lateral. The base is embedded in the lateral portio at 9 o'clock, from the apex embedded in the upper lateral vaginal wall at 2 to 3 o'clock. The cervical canal is difficult to evaluate.

It was decided to carry out an evacuation with a tenaculum on the body of the left side of the corpus alienum as the fixation for the pull, with a controlled pull to the left to expose the crest embedded in the left lateral vaginal wall. The lateral vaginal wall was bluntly removed until the top of the corpus alienum was fully exposed. The same is done on the left side of the base, the part that is embedded into the lateral portio is sharply removed using dissection scissors, after which it is released it can be evacuated out of the vagina. Re-evaluate and treat the bleeding that occurs. Cross suturing was performed on the torn lateral portion with PGA thread No. 2.0 until the bleeding stopped. The uterine ostium externum was exposed, performed sondage with uterine swabs, obtained a $9 \mathrm{~cm}$ anteflexion sondage size and a folley catheter no.16 was installed. spontaneous). In this case the patient was consulted to the psychiatry department and diagnosed with anxiety and depression disorder with fetishism and the patient received $1 \times 20 \mathrm{mg}$ oral fluoxetine therapy, and $1 \times 0.5 \mathrm{mg}$ alprazolam therapy. the patient was discharged on the 3rd postoperative day.

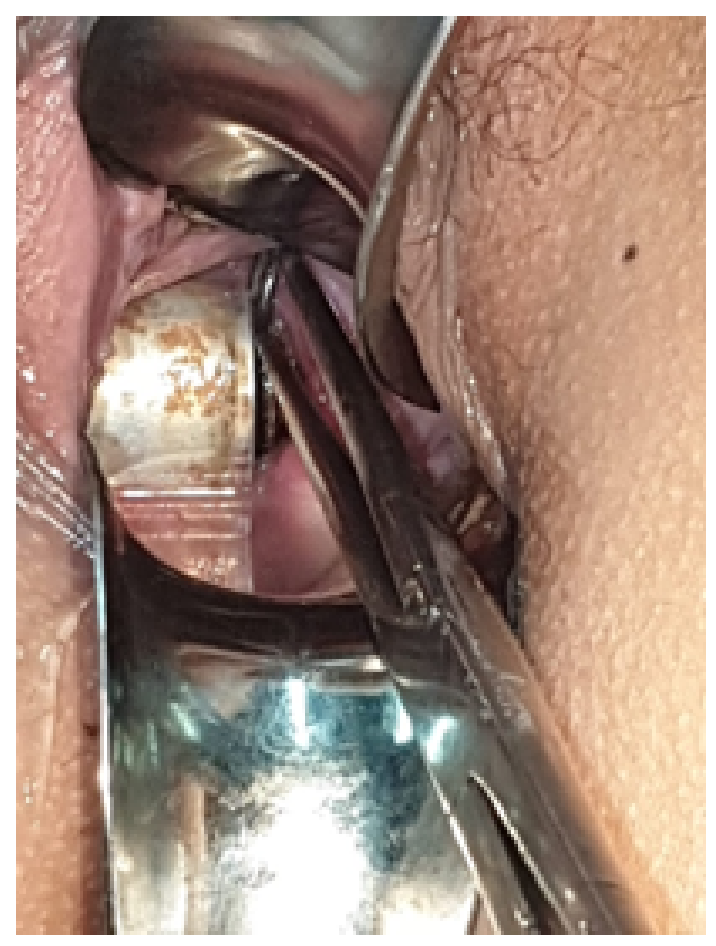

Fig. 1. Inspekulo

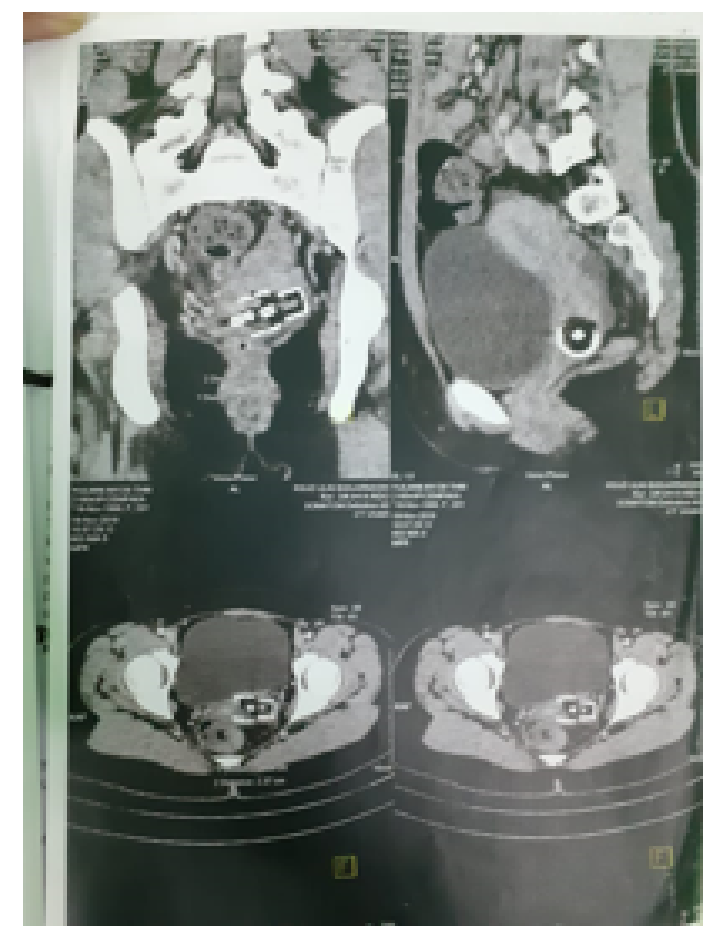

Fig. 2. Pelvic contrast CT scan 


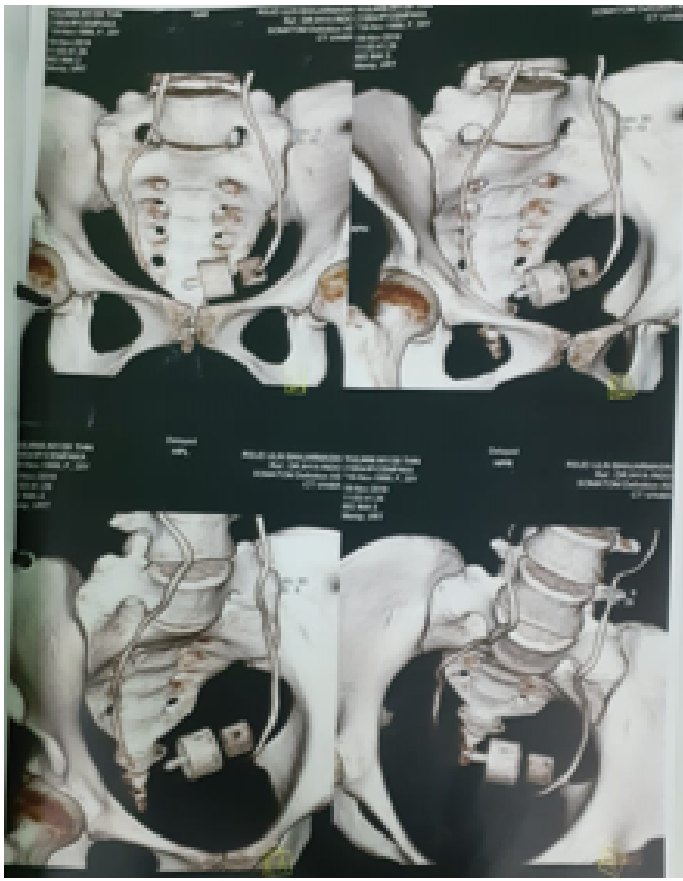

Fig. 3. Pelvic contrast CT scan

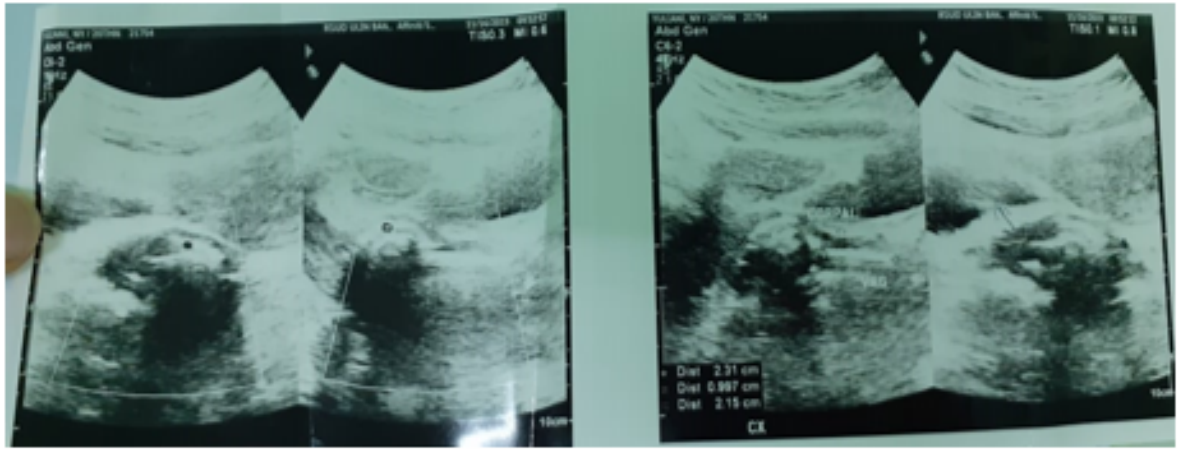

Fig. 4. USG abdomen

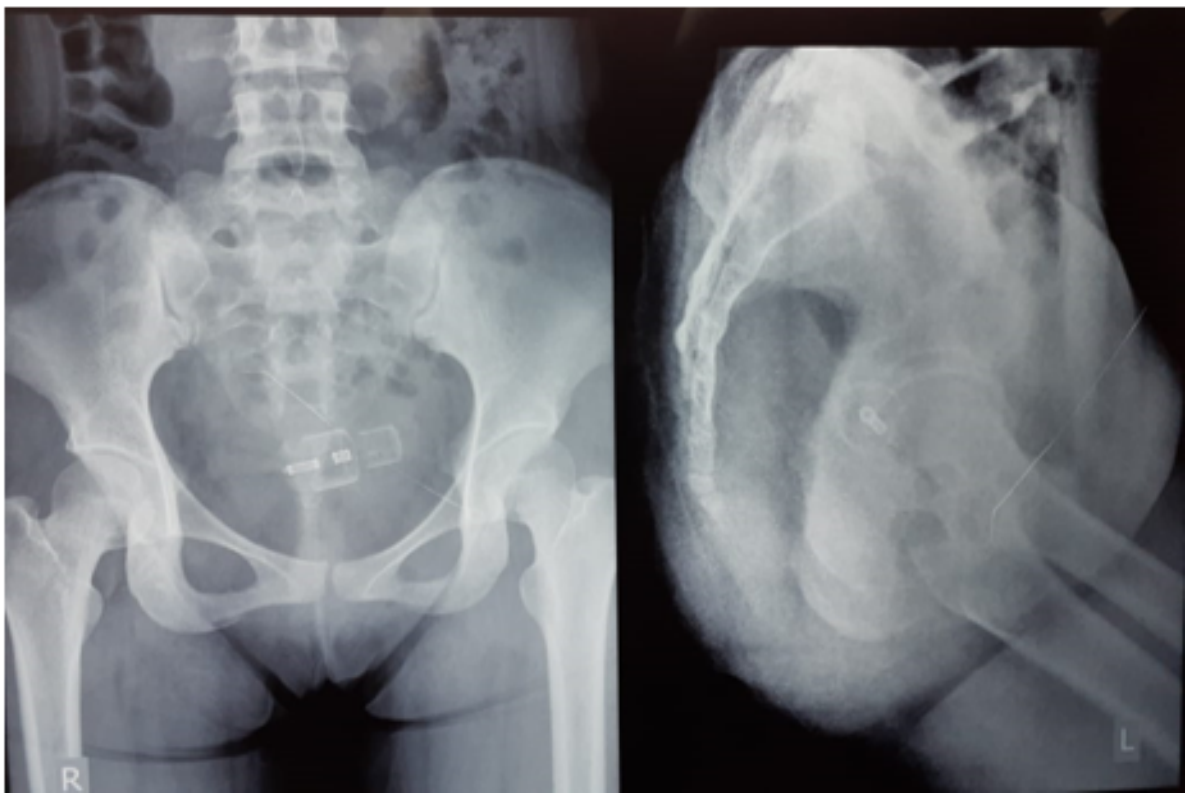

Fig. 5. Pelvis photo 
Fig. 6. Intraoperative corpal extraction

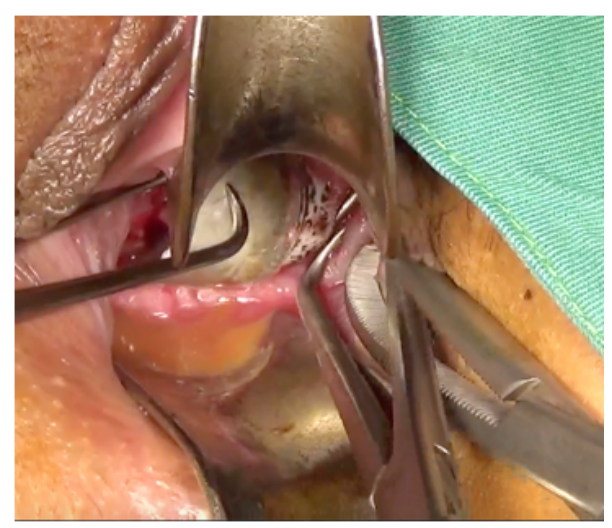

Fig. 6. Intraoperative corpal extraction

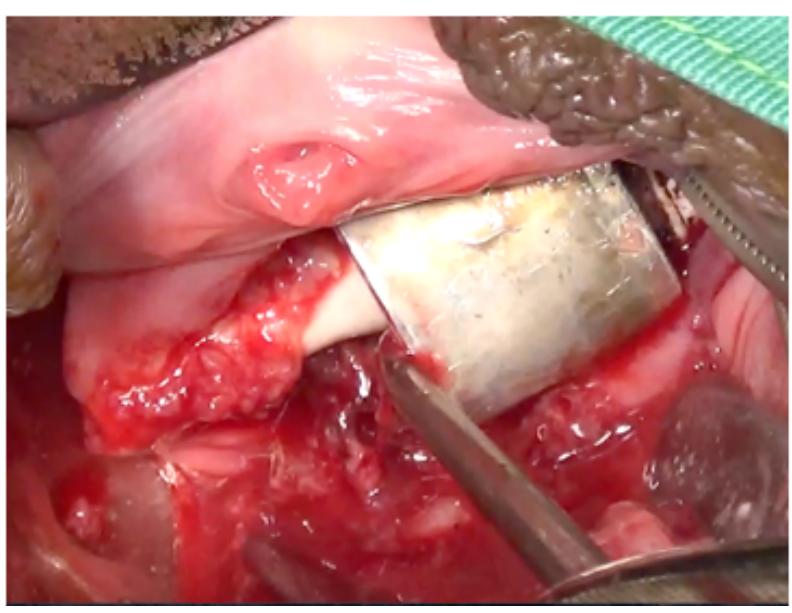

Fig. 7. Intraoperative corpal extraction

Fig. 8. Post operative

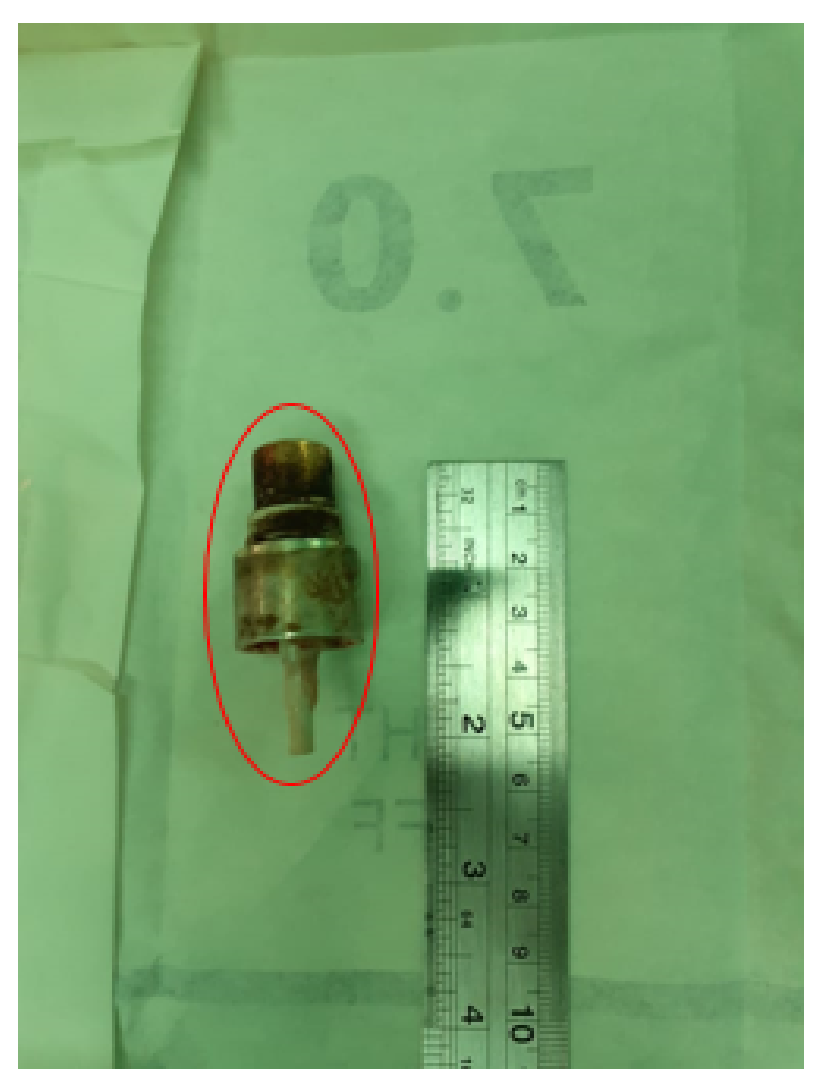


Fig. 9. Corpus alienum
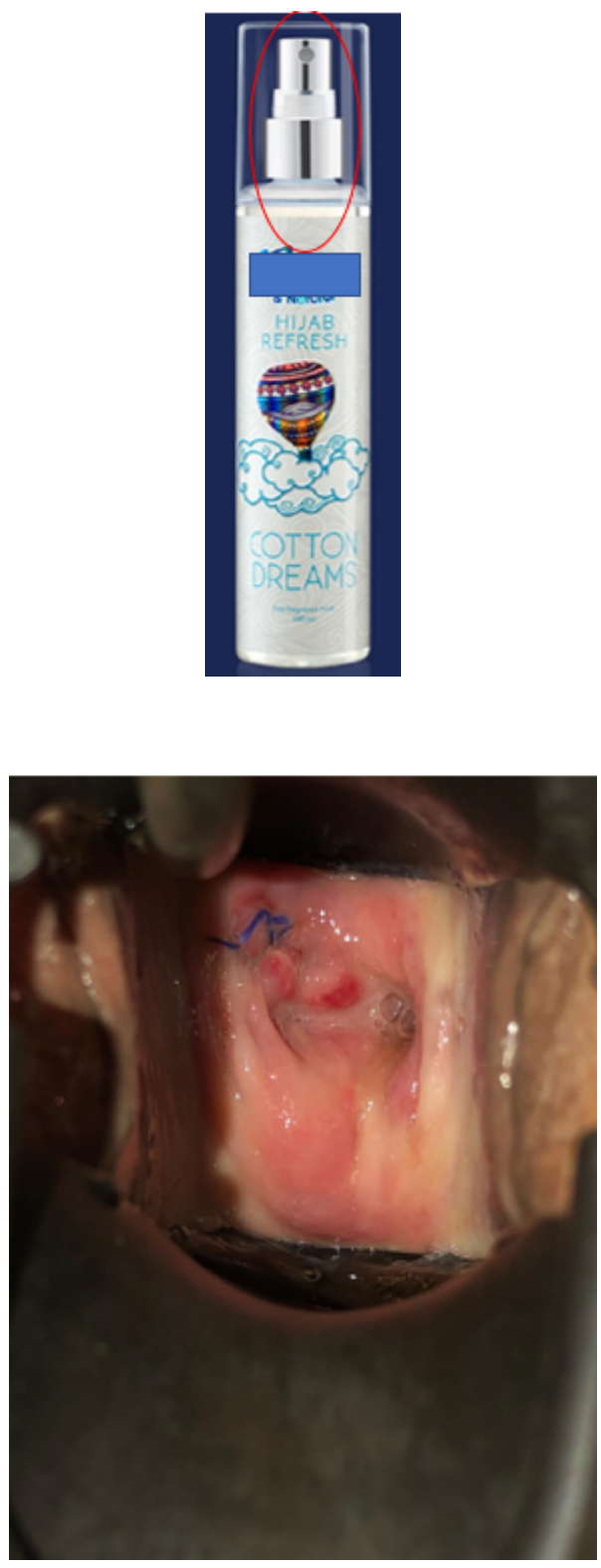

Fig. 10. Post operative day 10

\section{DISCUSSION AND CONCLUSION}

An object that is intentionally or unintentionally placed in the vagina is known as the corpus alienum. Corpus alienum may cause symptoms or cause no symptoms for a long period of time. If a small object is inserted into the vagina it is generally painless, but if it is an object that is larger than the normal diameter of the vagina or the size of the introitus it can cause distended pain. Other objects can cause pain due to sharp, irregular edges and because of infections that may build up. It is reported that several objects such as tampons, vaginal suppositories, drugs and contraceptives are designed for use in a woman's vagina. Leucorrhoea is a common gynecological complaint with many different etiologies. One of the rare causes is the presence of a foreign body in the genital tract. Foreign objects that are located in the genital tract can cause various clinical problems such as vaginal discharge, scar tissue in the vagina, fistula formation, recurrent urinary tract infections, causing infertility [4]

The corpus alienum, which is located in the genital tract, is one of the causes of vaginal discharge, especially in prepubertal women. Clinical suspicion will be high if the symptoms of vaginal discharge do not resolve after empirical treatment with antibiotics. For this reason, a careful and careful medical history and physical examination can easily make the diagnosis. The most common symptoms of corpus alienum are vaginal bleeding, bloody or smelly discharge. The treatment taken is the extraction of the foreign body, and simple irrigation with an antiseptic solution without any additional treatment required [5]. 
Corpus alienum in the vagina can cause severe inflammation that can cause bleeding and even foul-smelling vaginal discharge [6]. Other causes of vaginal bleeding include trauma, sexual abuse, vulvovaginitis, endocrine disorders, urethral prolapse, hemangioma, and tumors [7]. The corpus alienum can also change the normal flora of the vagina, resulting in repeated therapies that fail to treat cases considered vaginitis. Repeated use of antibiotics or other drugs will not improve symptoms if the corpus alienum is not taken. Although the corpus alienum remains in the vagina it rarely causes serious complications [8].

In this case, a 20-year-old woman who deliberately inserts a corpus alienum in the form of a perfume bottle into her vagina for 4 years in her vagina. The duration of the appearance of symptoms until the appearance of the diagnosis can vary, so that the corpus alienum in the vagina is not diagnosed for 2 or 3 years [8].

Foul-smelling vaginal bleeding is considered to be the main clinical manifestation of the corpus alienum in the vagina $[6,9,7,10]$. In this case the corpus alienum (perfume bottle cap) is deliberately inserted into the vagina for sexual satisfaction. Ultrasound examination can sometimes help in the diagnosis of the presence of a corpus alienum although sometimes a non-radiopaque corpus alienum will not be seen on radiographs. The definitive treatment is the removal of a foreign body. If the corpus alienum is located in the distal vagina, especially in the vaginal introitus, it can be removed or washed. Diagnosis and removal of a more proximal or implanted vaginal wall of the alienum usually requires vaginoscopy. Removal of foreign bodies followed by vaginal irrigation using providon iodine. In all patients the symptoms were completely cured without any additional treatment, so the use of a sitz bath after removal of a foreign object was unnecessary. There is no evidence that saline irrigation is significantly different from that without irrigation [5].

Various types of corpus alienum can be inserted into the vagina or rectum for sexual stimulation by women or their partners, such as liquor glasses, bottles, atomizer caps, and bottle caps [11]. [12] reported a case of removal of intrauterine logs that were retained for 12 years in the uterine fundus, under ultrasound guidance [12]. [13] reported hysteroscopic removal of the tip of cannula number 6 from the subvesical space [13]. [14] reported emphasizing the role of vaginography as an alternative diagnostic tool for detecting intravaginal foreign bodies [14].

Corpus alienum in adults is usually associated with masturbation, sexual intercourse, sexual abuse or psychiatric disorders [9]. In this patient, after a follow-up about his psychiatry, a psychiatric specialist diagnosed the patient with anxiety and depression with fetishism. It is known that fetishism is a condition in which a person has sexual urges related to inanimate objects. In this case a person becomes sexually aroused by wearing or touching an object, such as underwear, rubber clothing, or women's shoes. Fetish can replace sexual activity with a partner or can be integrated into sexual activity with a partner. When fetishes are the sole object of sexual desire sexual intercourse is often avoided [15]. The corpus alienum that is inserted deep in the vagina or uterus may not be visible at the introitus or when palpated as in this case it becomes a solid image due to the formation of granulation tissue. Plain X-rays or ultrasound of the pelvis are helpful but may not identify images of radioactive objects so that such objects will be well visualized with a CT scan [16].

\section{REFERENCES}

[1] Abduljabbar HS, Sbenati MA. Neglected intra-cervical bizarre foreign object. Saudi Medical Journal. 2012;33(12):1343-1345.

[2] Kharismadhany, Sari UE, Rakhmah QA. Increasing women's awareness on the importance of early detection of cervical cancer through socialization method and focus group discussion in Sabdodadi village Bantul Yogyakarta. Journal of Advances in Health and Medical Sciences. 2017;3(1):9-16. doi: https://doi.org/10.20474/jahms3.1.2.

[3] Niha S, Jantarasiriput B, Tonyongdalaw N, Vaichompu N. Reproductive health among bangoebadae muslim women: Cervical cancer care. International Journal of Health and Medical Sciences. 2016;2(3):52-57. doi: https://doi.org/10. 20469/ijhms.2.30002-3.

[4] Emge KR. Vaginal foreign body extraction by forceps: A case report. American Journal of Obstetrics and Gynecology. 1992;167(2):514-515. doi: https://doi.org/10.1016/s0002-9378(11)91444-6.

[5] Stricker T, Navratil F, Sennhauser F. Vaginal foreign bodies. Journal of Paediatrics and Child Health. 2004;40(4):205-207. doi: https://doi.org/10.1111/j.1440-1754.2004.00338.x.

[6] Sanfilippo J. Gynecologic problems of childhood. Philadelphia, PA: WB Saunders; 2000. 
[7] Emans SJ, Laufer M, Goldstein D. Vulvovaginal problems in the prepubertal child. Philadelphia, PA: Lippincott Williams \& Wilkins; 2012.

[8] Ambuel JP. Foreign bodies in the vagina of children. The Journal of Pediatrics. 1959;54(1):113-115. doi: https://doi. org/10.1016/S0022-3476(59)80047-0.

[9] Paradise JE, Willis ED. Probability of vaginal foreign body in girls with genital complaints. American Journal of Diseases of Children. 1985;139(5):472-476. doi: https://doi.org/10.1001/archpedi.1985.02140070046031.

[10] Templeman C, Hertweck S, Muram D, Sanfilippo J. Vaginal bleeding in childhood and menstrual disorders in adolescence. Philadelphia, PA: WB Saunders; 2001.

[11] Jaluvka V, Novak A. Vaginal foreign bodies in women in postmenopause and in senium. European Journal of Obstetrics \& Gynecology and Reproductive Biology. 1995;61(2):167-169. doi: https://doi.org/10.1016/0301-2115(95)02071-E.

[12] Roy K, Mittal S, Verma A. Removal of an intrauterine foreign body retained for 12 years. International Journal of Gynaecology and Obstetrics. 1996;54(2):185-186. doi: https://doi.org/10.1016/0020-7292(96)02702-6.

[13] Yazicioglu H, Yasar L, Dülger Ö. Hysteroscopic removal of a foreign body from the subvesical space. International Journal of Gynaecology and Obstetrics. 2004;86(1):48-49.

[14] Wu MH, Huang SC, Lin YS, Lin MF, Chou CY. Intravaginal foreign body retained for a long duration. International Journal of Gynecology \& Obstetrics. 1995;50(2):193-195. doi: https://doi.org/10.1016/0020-7292(95)02420-H.

[15] Medicine Net. Medical Definition of Fetishism; 2021. Available from: https://bit.ly/3iRj4yV.

[16] Chopra S, Singh Y, Magon N. A case of intravaginal foreign body. Medical Journal, Armed Forces India. 2010;66(3):266. doi: https://doi.org/10.1016/S0377-1237(10)80053-X. 